\title{
Study on Ohmic Heating Behavior of Fly Ash Filled Carbon Woven/Epoxy Resin Composite ${ }^{\star}$
}

\author{
Yuan-Feng Wang ${ }^{\text {a,*, }}$, Vijay Baheti ${ }^{\mathrm{b}}$, Kai Yang ${ }^{\mathrm{a}}$, \\ Mohanapriya Venkataraman ${ }^{\mathrm{a}}$, Tao Yang ${ }^{\mathrm{a}}$, Jiří Militkýa \\ a Department of Material Engineering, Technical University of Liberec, Studentská 1402/2, Liberec 1, \\ 46117 Czech Republic \\ ${ }^{\mathrm{b}}$ Department of Textile and Fibre Engineering, Indian Institute of Technology Delhi, Hauz Khas, New \\ Delhi 110016, India
}

\begin{abstract}
The Ohmic heating behavior and electrical property of the carbon fabric/green epoxy composite laminates filled with various concentrations of unmilled fly ash and milled fly ash were investigated in present work. We used an infrared camera to record the change in surface temperature of composites over a period of time by varying the voltage from 0 to $10 \mathrm{~V}$. The results show that the composite containing low concentration of fly ash exhibited the optimum Ohmic heating behavior under different applied voltages. The maximum temperatures of epoxy/carbon composites were adjustable by controlling the concentrations of fly ash fillers as well as the applied voltage. When a certain voltage was applied to the composite, the surface temperature of composite raised to the maximum within $20 \mathrm{~s}$ and became stable, then cool down to room temperature in $120 \mathrm{~s}$. In addition, the milled fly ash filled epoxy/carbon composites were found to reveal improvement in electrical heating performance and structural stability over the unmilled fly ash filled composites.
\end{abstract}

Keywords: Ohmic Heating; Fly Ash; Carbon Woven; Composite Laminates

\section{Introduction}

Over the past decade, multi-functional applications such as intelligent sensing, intelligent heating, and electrothermal performance have attracted a lot of research interest and conducted numerous research works. There is an overall intriguing interest to seek smart and Ohmic heating materials with superiorities on mechanical, stimuli-responsive and electrical properties [1]. Incorporating an electrically conductive filler such as metal fiber, graphite or other carbon materilas in polymer matrix was typically utilized to achieve this goal. Composite material prepared in this way can

${ }^{\star}$ Project supported by the student grant competition 21310 at Technical University of Liberec.

${ }^{*}$ Corresponding author.

Email address: yuanfeng.wang@tul.cz (Yuan-Feng Wang). 
be used as an Ohmic heating element, which generate heat by the passage of an electric current through a conductor according to the Joule's first law, also known as the Joule-Lenz law [2].

Epoxy/carbon composite is one of the typical examples of such Ohmic heating composites $[3,4]$. Epoxy resins, being organic, have high strength, good stiffness, good thermal stability, excellent heat, moisture and chemical resistance. Therefore, they have a wide range of applications including metal coatings, electronics/electrical components, electrical insulators, fiber-reinforced plastic materials, textile finishing, and structural adhesives [5]. For the last few decades, the inclusion of nanoscale carbon-based fillers such as carbon nanofibers [6], carbon nanotubes [7], graphene/graphite nanoplatelets [8], and carbon blacks [9] into insulating epoxy resins, have allowed to obtaining electrically conductive nanocomposites accompanied with unique mechanical and multi-functional properties. Epoxy-based composites reinforced with carbon-based nanofillers have been extensively investigated for the uses in advanced areas such as electromagnetic shielding, electronic components, capacitors, electrodes for rechargeable batteries, sensors and actuators [10].

However, under heating conditions, epoxy resin shows poor performance in structural stability due to its limited mechanical properties, shrinkage ratio and acclimatization [11]. To overcome these problems, during processing in previous studies, various fillers have been introduced into the resins [12, 13]. Most fillers used in the epoxy resins include inorganic [14], organic [15] and ceramic materials [16]. It is accepted that the properties of epoxy composites can be altered by the characteristics of the fillers including shape, size, volume fraction in the resin, as well as the modification of the filler surfaces. Waste fly ash particles is one of the widely used fillers. They are interesting because of their low density, low cost, strong filling ability, and smooth spherical surface.

Fly ash is the residue from combustion of pulverized coal in thermal power stations. It is a mixture of oxides and it is rich in silicon $\left(\mathrm{SiO}_{2}\right)$, iron $\left(\mathrm{Fe}_{2} \mathrm{O}_{3}\right)$, and aluminum $\left(\mathrm{Al}_{2} \mathrm{O}_{3}\right)$. The benefits of fly ash are recognized for a variety of structural products like sport equipment, insulation, automobile bodies, marine craft bodies, fire and heat protection devices [17]. Fly ash based light weight composite materials are also reported to be suitable in automotive, chemical and furniture manufacturing industries due to their improved strength, stiffness and thermal resistance. It has been shown that this type of filler enhances the mechanical properties of composites, especially for highly packed systems [18]. Thermal conductivity can also be improved through the addition of a greater amount of filler into the composites based on epoxy resin [19]. With higher packing and proper arrangement of filler particles, there is a higher possibility that heat transfer paths may be created in the composite [20], resulting in better heat dissipation.

The particle size and surface activity of fly ash play important roles in the interfacial properties of the interface between fly ash particles and matrix. The particle size of the filler is an important factor to govern the size of interface, whereas the surface of the filler determines the strength of the interface [21]. The surface of fly ash is usually modified based on silane or non-silane coupling agents [22]. However, there is limited information on the optimization of the fly ash particle size as well as its surface modification.

In the present study, ball milling process is employed to simultaneously modify, in a single stage, both the size and surface of fly ash particles. Carbon fabric/green epoxy composites containing various concentrations of milled and unmilled fly ash filler were fabricated by hand layup and using the cure technique. Ohmic heating and electrical property of the composite films were characterized using multi-ohmmeter and infrared camera. In addition, Ohmic heating behavior 
of the composites was discussed by considering the rapidity of temperature response, maximum temperature and electric power efficiency at different applied voltages.

\section{Experimental}

\subsection{Materials}

Green epoxy resin CHS-Epoxy G520 and hardener TELALIT 0600 were supplied by Spolchemie, Czech Republic. Fly ash particles with light gray in color and a density of $2 \mathrm{~g} / \mathrm{cm}^{3}$ were obtained from Plzeň, Czech Republic with the help of SILO Transport organization. Table 1 shows the main constituents of fly ash as determined by elemental analysis, where maximum amount of silica and alumina with traces of other metal oxides were listed. Based on the composition, fly ash was classified in class-F category (ASTM C618) as it contained more than $70 \%$ total content of silica and alumina together.

Table 1: Quantitative elemental analysis data of as received fly ash

\begin{tabular}{lcccccccccccccc}
\hline Element & $\mathrm{O}$ & $\mathrm{Na}$ & $\mathrm{Mg}$ & $\mathrm{Al}$ & $\mathrm{Si}$ & $\mathrm{P}$ & $\mathrm{S}$ & $\mathrm{K}$ & $\mathrm{Ca}$ & $\mathrm{Ti}$ & $\mathrm{Fe}$ & $\mathrm{Cu}$ & $\mathrm{As}$ & $\mathrm{Zr}$ \\
\hline Atomic [\%] & 53.80 & 1.84 & 1.06 & 14.27 & 20.25 & 0.09 & 0.19 & 0.25 & 0.94 & 1.95 & 4.72 & 0.16 & 0.15 & 0.34 \\
Standard deviation & 1.13 & 0.22 & 0.26 & 0.65 & 1.87 & 0.02 & 0.01 & 0.04 & 0.31 & 0.22 & 2.32 & 0.02 & 0.01 & 0.04 \\
\hline
\end{tabular}

\subsection{Milling of Fly Ash Particles}

The size of fly ash particles was refined to the micro/nano-scale using ball milling based on the previous research experience. The $30 \mathrm{~min}$ grinding was carried out by high-energy planetary ball mill of Fritsch Pulverisette 7, Germany in a sintered corundum container of $80 \mathrm{ml}$ capacity, using zirconium balls. The ball in terms of material ratio was kept at a scale of 10:1 and the speed was kept at $850 \mathrm{rpm}$. Afterwards, the distribution of a particle size of milled fly ash particles were characterize by Malvern zetasizer nano series based on dynamic light scattering principle of Brownian motion of particles. Deionized water was used as a dispersion medium and it was ultrasonicated for 5 minutes with Bandelin ultrasonic probe before characterization. In addition, microstructure of milled fly ash particles was observed using scanning electron microscope of TS5130-Tescan SEM, with an accelerating voltage of $20 \mathrm{kV}$. The amount of $0.01 \mathrm{~g}$ of fly ash particles was dispersed in $100 \mathrm{ml}$ acetone and then a drop of the dispersed solution was placed on aluminum foil.

\subsection{Preparation of Composites}

The composite samples were fabricated by the hand layup technique taking carbon woven fabric to epoxy weight ratio of 50:50. When fly ash fillers were added, weight fraction of epoxy resin was reduced, and carbon woven fabric weight fraction was fixed at $50 \%$. The details are listed in Table 2 below. The calculated amount of dried fly ash particles for $0.5,1$, and $3 \mathrm{wt} \%$ loading was mechanically mixed with epoxy resin at room temperature until a homogenous mixture was 
obtained. Then, the mixture was ultrasonicated under Bandelin sonoplus for 30 min using horn power of $60 \%$. After the application of fly ash filled green epoxy resin on every individual layer of the carbon woven fabric, the three layers of carbon woven fabrics were stacked one on another. A porous teflon film was used to complete the stack, and a $3 \mathrm{~mm}$ spacer was used to ensure uniform thickness of the composite samples. The whole assembly was placed in the convection oven under a predetermined pressure of $50 \mathrm{kPa}$ and left to cure at $120^{\circ} \mathrm{C}$ for $30 \mathrm{~min}$.

Table 2: Details of composite samples

\begin{tabular}{|c|c|c|c|c|}
\hline Sample code & Sample description & Fabric wt $\%$ & Epoxy wt\% & Fly ash wt $\%$ \\
\hline $3 \mathrm{CWF}+\mathrm{GE}+0.5 \% \mathrm{UMFA}$ & $\begin{array}{l}3 \text { layers of carbon fabric }+ \text { green epoxy } \\
+0.5 \% \text { unmilled fly ash }\end{array}$ & 50 & 49.5 & 0.5 \\
\hline $3 \mathrm{CWF}+\mathrm{GE}+1 \% \mathrm{UMFA}$ & $\begin{array}{l}3 \text { layers of carbon fabric }+ \text { green epoxy } \\
+1 \% \text { unmilled fly ash }\end{array}$ & 50 & 49 & 1 \\
\hline $3 \mathrm{CWF}+\mathrm{GE}+3 \% \mathrm{UMFA}$ & $\begin{array}{l}3 \text { layers of carbon fabric }+ \text { green epoxy } \\
+3 \% \text { unmilled fly ash }\end{array}$ & 50 & 47 & 3 \\
\hline $3 \mathrm{CWF}+\mathrm{GE}+0.5 \% \mathrm{MFA}$ & $\begin{array}{l}3 \text { layers of carbon fabric }+ \text { green epoxy } \\
+0.5 \% \text { milled fly ash }\end{array}$ & 50 & 49.5 & 0.5 \\
\hline $3 \mathrm{CWF}+\mathrm{GE}+1 \% \mathrm{MFA}$ & $\begin{array}{l}3 \text { layers of carbon fabric }+ \text { green epoxy } \\
+1 \% \text { milled fly ash }\end{array}$ & 50 & 47 & 1 \\
\hline $3 \mathrm{CWF}+\mathrm{GE}+3 \% \mathrm{MFA}$ & $\begin{array}{l}3 \text { layers of carbon fabric }+ \text { green epoxy } \\
+3 \% \text { milled fly ash }\end{array}$ & 50 & 45 & 3 \\
\hline
\end{tabular}

\subsection{Ohmic Heating}

The heating behavior of composite samples was characterized using a test setup as illustrated in Fig. 1. The composite sample was connected to the electrical power supply (TIPA SP3010) with a clamping distance of two centimeters. An infrared camera (FLIR-E6390, FLIR SWEDEN) was used to monitor the temperature distribution on the sample surface. When the voltage was increased from $0 \mathrm{~V}$ to $10 \mathrm{~V}$, the average temperature over the middle section between two electrodes was measured. Time dependence of surface temperature and electric current of test samples were detected under applied voltages by using the above system.

\section{$3 \quad$ Result and Discuss}

\subsection{Surface Morphology of Fly Ash and Carbon/Epoxy Composites}

Fig. 2(a) shows the particle size distribution of fly ash after 30 min of dry milling. It is obvious that after the grinding the particle size of fly ash was reduced greatly. The unmilled fly ash with particle diameter of $3547 \mathrm{~nm}$ was reduced to smaller particles of below $1000 \mathrm{~nm}$ diameter. For 


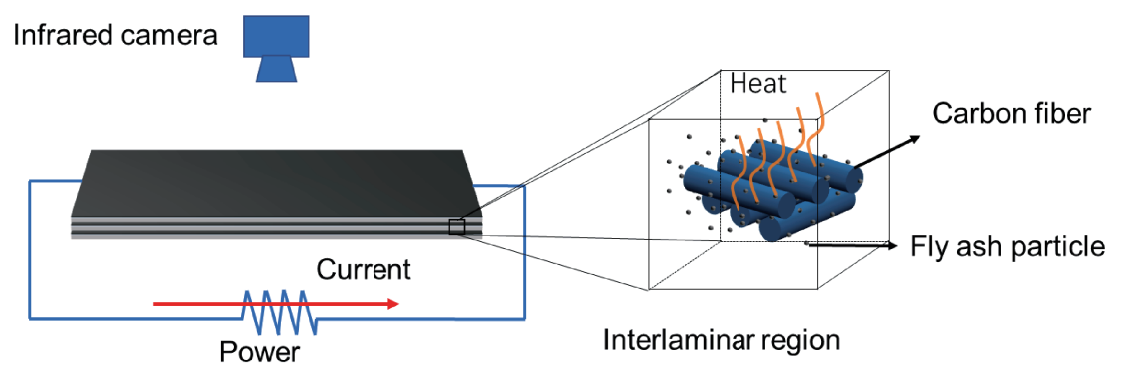

Fig. 1: Setup for temperature measurement
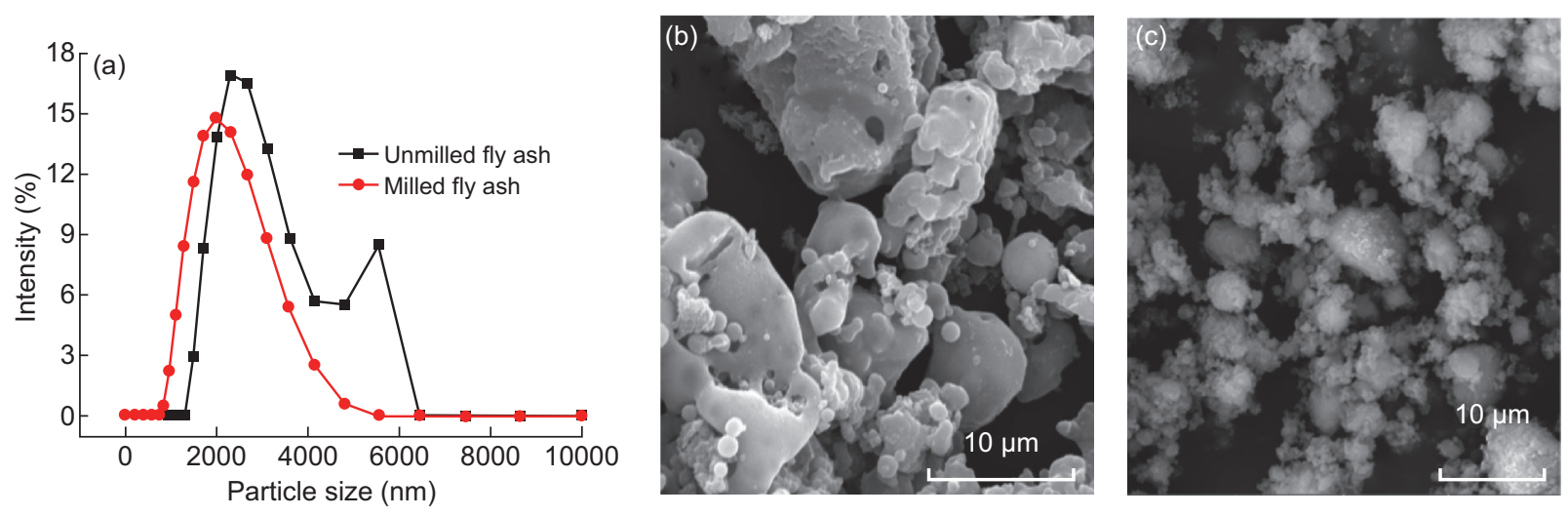

Fig. 2: Particle size distribution of fly ash (a) and SEM image of unmilled fly ash (a) and milled fly ash (b)

observation of surface morphology of fly ash particles, SEM images of unmilled and 30 min milled fly ash particles were taken. Fig. 2(b) and (c) show surface morphology of fly ash before and after milling. It can be seen that the size of fly ash particles was significantly reduced after the milling, which subsequently resulted into nano/micro fly ash with more active surfaces [23].

The surface SEM images of fly ash filled carbon/epoxy composites with a scale of $200 \mu \mathrm{m}$ was shown in Fig. 3. It can be seen that the fly ash particles were distributed on the surface of composites. Moreover, when increasing the fly ash concentration, a dense filling was formed on the composite surfaces. With the increase of unmilled fly ash concentration, larger particle size of particles can be observed on the composite surface, which indicated their agglomeration tendency at high fly ash concentration.

\subsection{Electrical Property of Composite}

Fig. 4 shows the current change depend on the voltage applied on the carbon-based composite samples with various concentrations of UFA (a) and FA (b), respectively. The applied voltage increased from $1 \mathrm{~V}$ to $9 \mathrm{~V}$ with the interval of $1 \mathrm{~V}$. In Fig. 4, for all the composite samples, the current increased linearly with the applied voltage, obeying to the Ohm's law. It can be seen that the slopes of the I-V curves became lower with the changing of the concentration of FA from $0.5 \%$ to $3 \%$. This phenomenon indicates that the electrical property of the composites increased with a decrease of FA concentration. When comparing FA and UFA samples, the currents of FA samples were significantly higher than the UFA samples under the same applied voltage. This can be explained by the reduced particle size of and optimized distribution of the milled FA particles, 

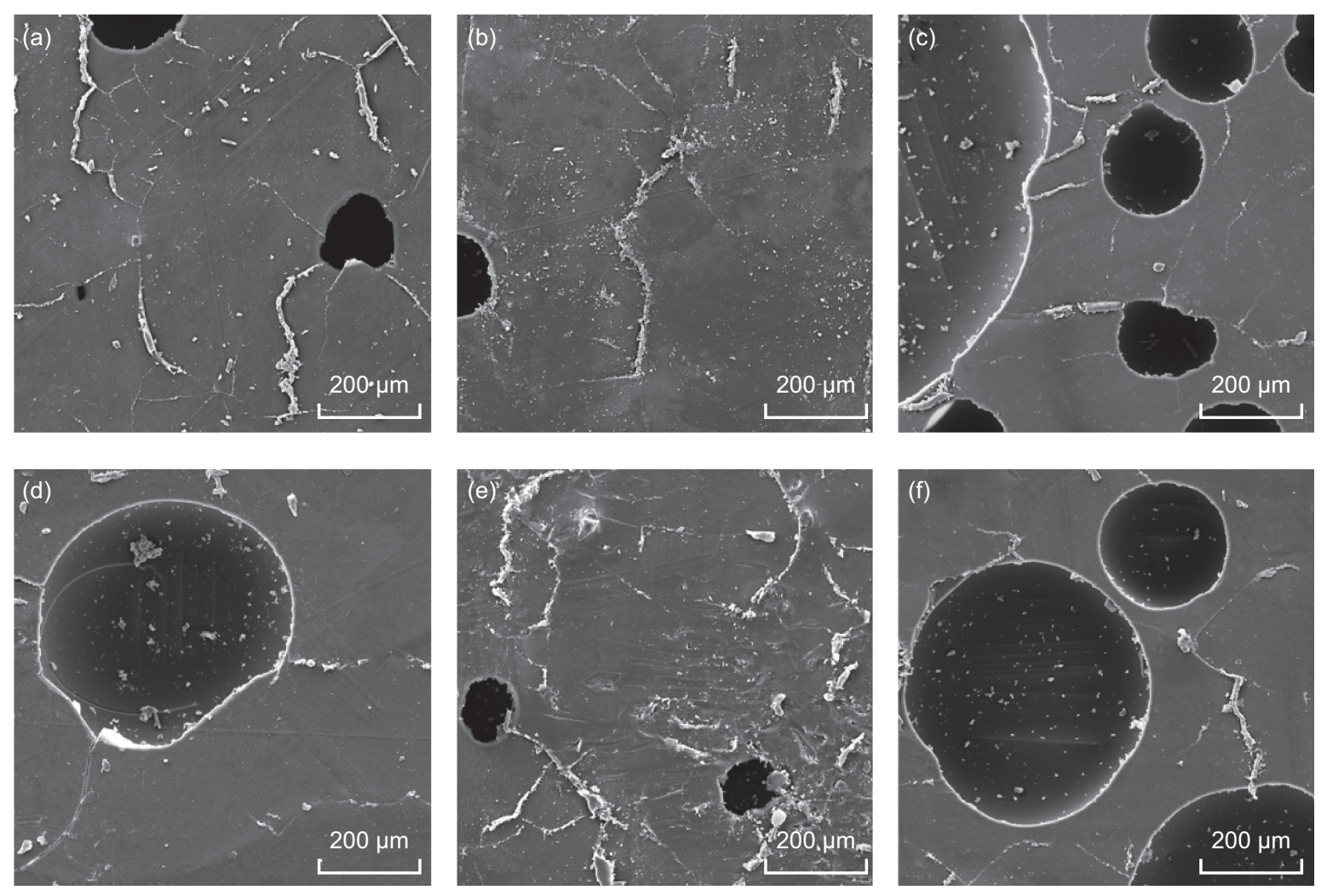

Fig. 3: Surface structure of fly ash filled composites (a) $0.5 \%$ UFA (b) $1 \%$ UFA (c) $3 \%$ UFA (d) $0.5 \%$ FA (e) $1 \%$ FA and (f) $3 \%$ FA
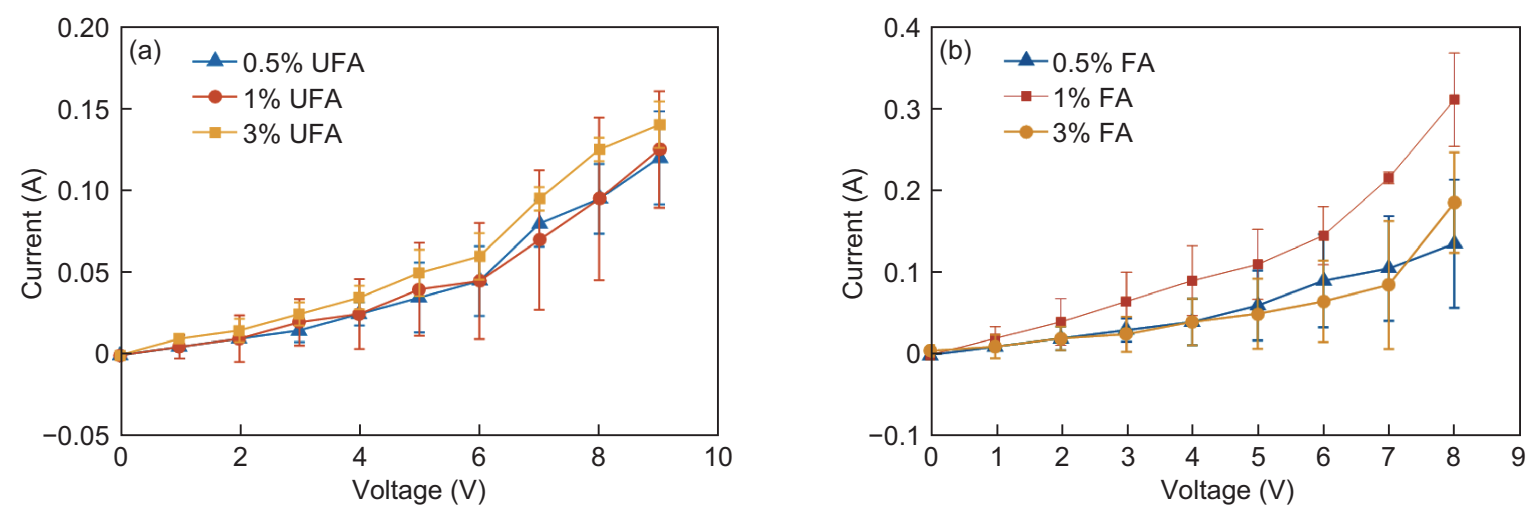

Fig. 4: Current of composite UFA (a) and FA (b) under different voltages

which dispersed uniformly into the epoxy matrix and optimized the structure of the composites with subsequent improvement of electrical conductivity of the samples.

\subsection{Ohmic Heating Property of Composite}

The investigation of surface temperature of composites with various concentrations of FA and UFA was carried out under applied voltage of $0-9$ V. Fig. 5 shows the temperature - voltage $(\mathrm{T}-\mathrm{V})$ curves of the composite samples FA(a) and UFA(b), respectively. It can be seen that in the T-V curves, the surface temperature remained almost the same without any remarkable change when 
a low voltage $(\mathrm{V}<4 \mathrm{~V})$ was supplied. After that, the surface temperature of composites increases with increasing voltage can be observed. When the same voltage is supplied, the temperatures of low concentration FA and UFA composites were obviously higher than other samples, which was due to the better electric conductivity as discussed before. By comparing the samples before and after milling, the temperature curve of $\mathrm{FA}$ is more stable and regular, which indicates that the milled FA particles are beneficial to improve the thermal stability of the composite due to the particle size and active particle surface.
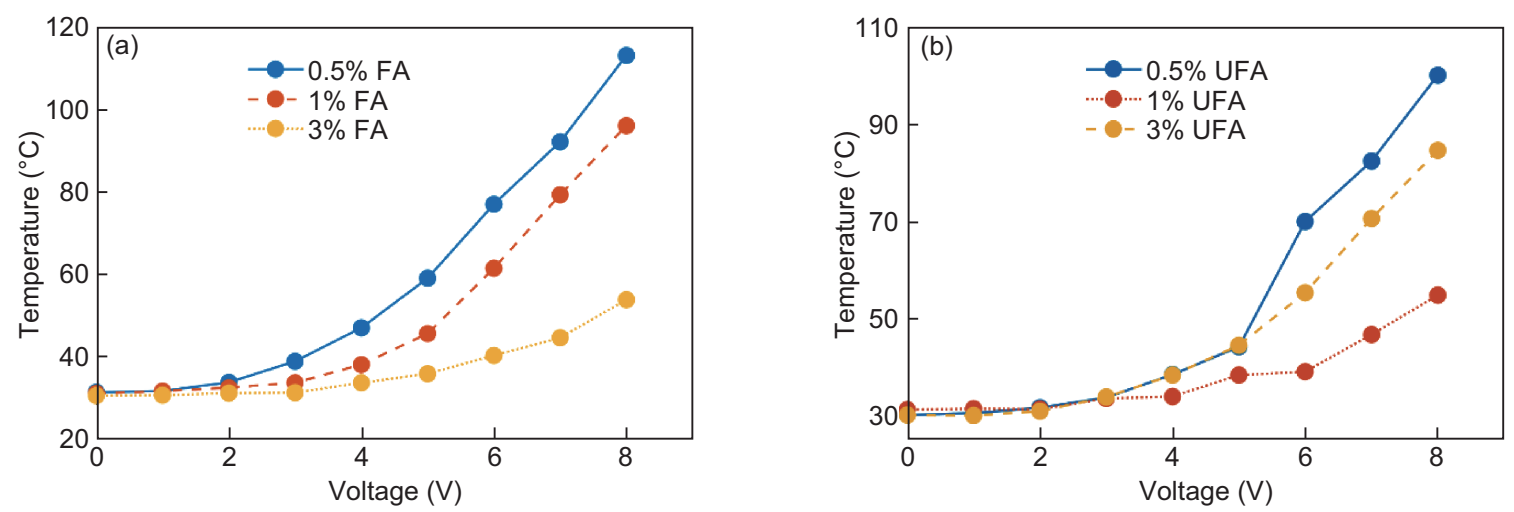

Fig. 5: Surface temperature of composite FA (a) and UFA (b) under different voltages

To further investigate the electric heating behavior of the carbon-based composite with various concentrations of FA and UFA, constant voltage was applied to evaluate the time- temperature characteristic of the composites. Fig. 6 shows the resulting time-dependent temperature changes of the composites. It is obviously that for all the composites, the temperature increased steeply once the voltage was applied at $0 \mathrm{~s}$, and then, after $30 \mathrm{~s}$, the rate of temperature increase became gentle and reached the maximum temperature at $120 \mathrm{~s}$. It kept up with the time and it decreased quickly to room temperature at $240 \mathrm{~s}$, when the applied voltage was off at $120 \mathrm{~s}$. It can be noted that the stable temperature increases by Joule heating greatly depends on the concentration of FA of composite samples. The leveling-off temperature becomes higher with decreasing FA content at the same applied voltage. It is clear that, under the same applied voltage, the magnitude of maximum temperature for the $0.5 \% \mathrm{FA}$ and UFA composites is higher than the other two composites, the $1 \%$ and $3 \%$ composites. When comparing the FA before and after milling, the curves of milled FA composites in the equilibrium section (30 s-120 s) are much smoother and the maximum temperatures are higher as well. This observation clarifies that the milled FA particles improve the tidiness of composite network structure and it promotes the heating efficiency and stability of composite.

To pursue more detailed analysis for the characteristic thermal properties we introduce three parameters, namely, characteristic growth time constant $\tau_{g}$, efficiency of heat transfer $h_{r+c}$ and characteristic decay time constant $\tau_{d}$ [24]. The time-dependent temperature curves in Fig. 6 could be divided into three sections: the temperature growth (heating) section $(0-30 \mathrm{~s})$, the equilibrium (maximum temperature) section (30-120 s), and the temperature decay (cooling) section $(120-240 \mathrm{~s})$.

At the first section, the increase of temperature with time can be empirically expressed as:

$$
\frac{T_{t}-T_{0}}{T_{m}-T_{0}}=1-e^{\left(-t / \tau_{g}\right)}
$$


where $T_{0}$ and $T_{m}$ are the initial ambient and the maximum temperatures, respectively. $T_{t}$ is the arbitrary temperature at time $t . \tau_{g}$ is the characteristic growth time constant. For the composites showing electric heating behavior, the $\tau_{g}$ values could be calculated by fitting the data in the first section of temperature versus time plots. The resulting values for all the composites are listed in Table 1. The value of $\tau_{g}$ for the $1 \%$ and $3 \% \mathrm{FA}$ composites show much longer $\tau_{g}$ than that of the $0.5 \%$ FA composite because of their lower conductivity. The same phenomenon can also be observed in the UFA samples.

In the second region of equilibrium, the maximum temperatures at each applied voltage remained unchanged by conservation law of energy, meaning that heat gain by electric power is equal to heat loss by radiation and convection. The heat transferred by radiation and convection, $h_{r+c}$, is thus expressed as:

$$
h_{r+c}=\frac{I_{c} V_{0}}{T_{m}-T_{0}}
$$

where $I_{c}$ is the steady-state current and $V_{0}$ is the applied voltage. Accordingly, the $h_{r+c}$ values could be calculated. It can be seen in Table 3 that the $h_{r+c}$ increases as FA content increases, indicating that relatively higher electrical energy is required to maintain the maximum temperatures.

In the third region, the composite films at maximum temperatures are left to cool down to the ambient temperature according to Newton's law of cooling. The latter states that the rate of change of the temperature of an object is proportional to the difference between its own temperature and the ambient temperature. Therefore, the temperature decreases with time, which can be described by the following empirical formula:

$$
\frac{T_{t}-T_{0}}{T_{m}-T_{0}}=e^{\left(-t / \tau_{d}\right)}
$$

where $\tau_{d}$ is the characteristic decay time constant. Accordingly, the $\tau_{d}$ values could be calculated by fitting experimental time-dependent temperature decay data, as summarized in Table 3.

It is also noticeable that the $\tau_{g}$ and $\tau_{d}$ values of the composite with $0.5 \%$ FA and UFA were lower than the ones with 1\% FA and UFA composites. This means that the lower content FA composite exhibited unusually rapid temperature responses to applied voltages as well as it is easier to control.
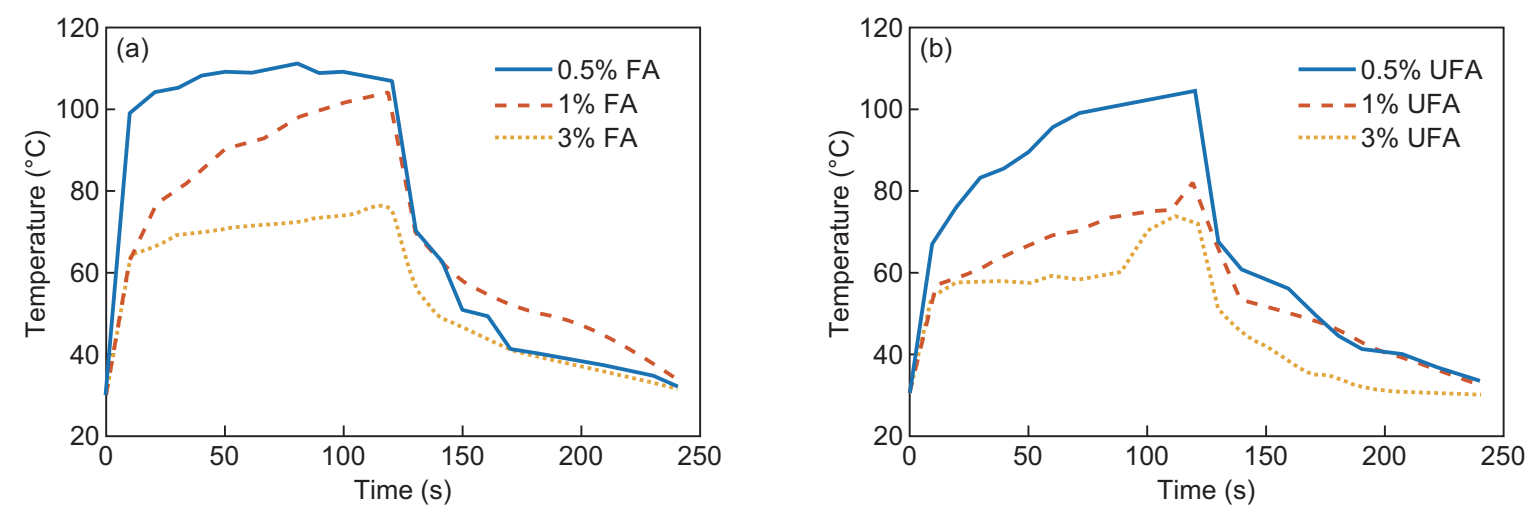

Fig. 6: Time-dependent temperature changes of composite FA (a) and UFA (b) 
Table 3: Characteristic parameters $\left(\tau_{g}, h_{r+c}\right.$, and $\left.\tau_{d}\right)$ for electric heating performance of composites with different concentrations of FA and UFA under applied voltages

\begin{tabular}{cccc}
\hline Samples & $\tau_{g}[\mathrm{~S}]$ & $h_{r+c}\left[\mathrm{~mW} /{ }^{\circ} \mathrm{C}\right]$ & $\tau_{d}[\mathrm{~S}]$ \\
\hline $0.5 \% \mathrm{FA}$ & $8.31 \pm 3.15$ & 18.79 & $103.67 \pm 34.177$ \\
$1 \% \mathrm{FA}$ & $21.21 \pm 4.88$ & 22.73 & $139.90 \pm 32.25$ \\
$3 \% \mathrm{FA}$ & $12.22 \pm 4.24$ & 8.89 & $115.12 \pm 44.56$ \\
$0.5 \% \mathrm{UFA}$ & $19.70 \pm 4.84$ & 14.09 & $121.79 \pm 34.99$ \\
$1 \% \mathrm{UFA}$ & $25.15 \pm 10.12$ & 19.55 & $144.25 \pm 53.76$ \\
$3 \%$ UFA & $20.83 \pm 9.17$ & 21.91 & $73.67 \pm 32.81$ \\
\hline
\end{tabular}

\section{Conclusion}

The concept of fly ash incorporation into carbon woven/epoxy laminated composites was found to be a very useful way to utilize fly ash waste as a composite stabilizer. The high energy wet milling process is simple, economical and a faster method to optimize particle size and activate the surface of fly ash. Various concentrations of milled and unmilled nanoparticles were filled into epoxy matrix and the mixture was applied in between each layer of carbon woven fabric to prepare a three-layered laminated composite. The electric conductivity and Ohmic heating characteristics of carbon woven/epoxy composites strongly depend on the concentration of fly ash filler. As the fly ash content increases, the electrical conductivity of the composite decreases. The maximum temperatures of epoxy/carbon composites were adjustable by controlling the concentrations of fly ash fillers as well as the applied electric power. When a certain voltage was applied to the composite, the surface temperature of composite raised to the maximum within $20 \mathrm{~s}$ and became stable, then cool down to room temperature in $120 \mathrm{~s}$. In addition, the milled fly ash filled epoxy/carbon composites were found to reveal improvement in electrical heating performance and structural stability over the unmilled fly ash filled composites. Overall, it is highly conjectured that epoxy/carbon/fly ash composites, which prove to have the characteristic of quick heating as well as wide adjustability of temperature with the thermally stable up to $110{ }^{\circ} \mathrm{C}$, can be widely used in various fields.

\section{Acknowledgement}

This work was supported by the student grant competition 21310 at Technical University of Liberec.

\section{References}

[1] Zhang Q, Yu Y, Yang K, et al. Mechanically robust and electrically conductive graphene-paper/ glass-fibers/epoxy composites for stimuli-responsive sensors and Joule heating deicers. Carbon: 2017; 124: 296-307. 
[2] Kim GM, Naeem F, Kim HK, et al. Heating and heat-dependent mechanical characteristics of CNT-embedded cementitious composites. Composite Structures: 2016; 136: 162-170.

[3] Alian AR, Kundalwal SI, Meguid SA. Multiscale modeling of carbon nanotube epoxy composites. Polymer: 2015; 70: 149-160.

[4] Ray BC. Temperature effect during humid ageing on interfaces of glass and carbon fibers reinforced epoxy composites. Journal of colloid and interface science: 2006; 298(1): 111-117.

[5] Chen H, Jacobs O, Wu W, et al. Effect of dispersion method on tribological properties of carbon nanotube reinforced epoxy resin composites. Polymer Testing: 2007; 26(3): 351-360.

[6] Choi YK, Sugimoto K, Song SM, et al. Mechanical and physical properties of epoxy composites reinforced by vapor grown carbon nanofibers. Carbon: 2005; 43(10): 2199-2208.

[7] Park JG, Cheng Q, Lu J, et al. Thermal conductivity of MWCNT/epoxy composites: the effects of length, alignment and functionalization. Carbon: 2012; 50(6): 2083-2090.

[8] Song SH, Park KH, Kim BH, et al. Enhanced thermal conductivity of epoxy-graphene composites by using non-oxidized graphene flakes with non-covalent functionalization. Advanced Materials: 2013; 25(5): 732-737.

[9] Trihotri M, Dwivedi UK, Khan FH, et al. Effect of curing on activation energy and dielectric properties of carbon black-epoxy composites at different temperatures. Journal of Non-Crystalline Solids: 2015; 421: 1-13.

[10] Jeong YG, An JE. Effects of mixed carbon filler composition on electric heating behavior of thermally-cured epoxy-based composite films. Composites Part A: Applied Science and Manufacturing: $2014 ; 56: 1-7$.

[11] Huang F, Liu Y, Zhang X, et al. Effect of elastomeric nanoparticles on toughness and heat resistance of epoxy resins. Macromolecular rapid communications: 2002; 23(13): 786-790.

[12] Ramakrishna HV, Priya SP, Rai SK. Utilization of flyash as filler for polybutyleneterepthalatetoughened epoxy resin. Polymer Engineering \& Science: 2006; 46(7): 946-953.

[13] Chaowasakoo T, Sombatsompop N. Mechanical and morphological properties of fly ash/epoxy composites using conventional thermal and microwave curing methods. Composites Science and Technology: 2007; 67(11-12): 2282-2291.

[14] Jin FL, Park SJ. Thermal properties of epoxy resin/filler hybrid composites. Polymer degradation and stability: 2012; 97(11): 2148-2153.

[15] Liu X, Wu Y, Yu Z. Tribological Properties of Organic Functionalized $\mathrm{ZrB}_{2}-\mathrm{Al}_{2} \mathrm{O}_{3}$ /Epoxy Composites. Tribology Letters: 2017; 65(1): 14.

[16] Luo B, Wang X, Zhao Q, et al. Synthesis, characterization and dielectric properties of surface functionalized ferroelectric ceramic/epoxy resin composites with high dielectric permittivity. Composites Science and Technology: 2015; 112: 1-7.

[17] Yao W, Zhao Y, Wu K, et al. Effect of fly ash on the structure and properties of polyolefin elastomer/fly ash/polypropylene composites. Materials Research Express: 2018; 6(2): 025308.

[18] Sroka J, Rybak A, Sekula R, et al. Two-Step procedure of fly ash modification as an alternative method for creation of functional composite. Journal of Polymers and the Environment: 2017; 25(4): 1342-1347.

[19] Dorigato A, Sebastiani M, Pegoretti A, et al. Effect of silica nanoparticles on the mechanical performances of poly (lactic acid). Journal of Polymers and the Environment: 2012; 20(3): 713725 .

[20] Gaska K, Kmita G, Rybak A, et al. Magnetic-aligned, magnetite-filled epoxy composites with enhanced thermal conductivity. Journal of materials science: 2015; 50(6): 2510-2516.

[21] Baheti V, Militky J, Mishra R, et al. Thermomechanical properties of glass fabric/epoxy composites filled with fly ash. Composites Part B: Engineering: 2016; 85: 268-276. 
[22] Sroka J, Rybak A, Sekula R, et al. An investigation into the influence of filler silanization conditions on mechanical and thermal parameters of epoxy resin-fly ash composites. Journal of Polymers and the Environment: 2016; 24(4): 298-308.

[23] Khan, Muhammad Z, et al. Superhydrophobicity, UV protection and oil/water separation properties of fly ash/Trimethoxy (octadecyl) silane coated cotton fabrics. Carbohydrate polymers: 2018; 202: $571-580$.

[24] El-Tantawy F, Kamada K, Ohnabe H. In situ network structure, electrical and thermal properties of conductive epoxy resin-carbon black composites for electrical heater applications. Materials Letters: $2002 ; 56(1-2): 112-126$. 